\title{
Structure and Transcription of the Drosophila melanogaster Vermilion Gene and Several Mutant Alleles
}

\author{
LILLIE L. SEARLES, * RICHARD S. RUTH, ANNE-MARIE PRET, ROBERT A. FRIDELL, AND AHMAD J. ALI \\ Department of Biology, The University of North Carolina at Chapel Hill, Chapel Hill, North Carolina 27599-3280
}

\author{
Received 19 September 1989/Accepted 15 December 1989
}

\begin{abstract}
The nucleotide sequence and intron-exon structure of the Drosophila melanogaster vermilion (v) gene have been determined. In addition, the sites of several mutations and the effects of these mutations on transcription have been examined. The major $v$ mRNA is generated upon splicing six exons of lengths $\left(5^{\prime}\right.$ to $\left.3^{\prime}\right) 83,161,134$, 607, 94, and 227 nucleotides (nt). A minor species of $v$ mRNA is initiated at an upstream site and has a $5^{\prime}$ exon of at least $152 \mathrm{nt}$ which overlaps the region included in the 83-nt exon of the major $v$ RNA. The three $v$ mutations, $v^{1}, v^{2}$, and $v^{k}$, which can be suppressed by mutations at suppressor of sable, su(s), are insertions of transposon 412 at the same position in exon 1, $36 \mathrm{nt}$ downstream of the major transcription initiation site. Despite the 7.5-kilobase insertion in these $v$ alleles, a reduced level of wild-type-sized mRNA accumulates in suppressed mutant strains. The structure and transcription of several unsuppressible $v$ alleles have also been examined. The $v^{36 f}$ mutation is a B104/roo insertion in intron 4 near the splice donor site. A mutant carrying this alteration accumulates a very low level of mRNA that is apparently polyadenylated at a site within the B104/roo transposon. The $v^{48 a}$ mutation, which deletes approximately $200 \mathrm{nt}$ of DNA, fuses portions of exons 3 and 4 without disruption of the translational reading frame. A smaller transcript accumulates at a wild-type level, and thus an altered, nonfunctional polypeptide is likely to be synthesized in strains carrying this mutation. The $v^{\mathrm{H} 2 \mathrm{a}}$ mutant has a $\mathrm{P}$ element insertion in exon 6 within the coding region.
\end{abstract}

Several mutations at the Drosophila melanogaster vermilion $(v)$ gene can be suppressed by recessive mutations at suppressor of sable, $s u(s)$. The suppressible $v$ mutants have insertions of the retrotransposon 412 in the $v$ gene region $(36$, 43) and thus resemble other mutants with suppressible transposon insertion mutations in D. melanogaster. For example, suppressor of Hairy-wing, $s u(H w)$, and suppressor of forked, $s u(f)$, suppress gypsy element insertion mutations at several genes; suppressor of white apricot, $s u\left(w^{a}\right)$, and suppressor of sable, $s u(s)$, suppress copia and 412 insertion mutations, respectively $(4,19,22,23,36,43$; reviewed in reference 13). These mobile elements are all retrotransposons, a group of structurally homologous elements that resemble the integrated form of mammalian retroviruses and make up the largest family of transposons in D. melanogaster (31). The major transcription products of these elements are nearly full-length, polyadenylated [poly $\left.(\mathrm{A})^{+}\right]$RNAs, and transcription of the elements is temporally regulated $(24,34)$. In an effort to understand the basis of suppression, genes with suppressible mutations $(15,22,23,27,36,48)$, as well as the suppressor genes $(7,25,39,46,47)$, are being cloned and studied at the molecular level. The transposon insertions associated with most suppressible mutations are located either in 5' untranscribed sequences or within introns. The mobile-element insertions typically interfere with synthesis of mRNA from a gene at or near the insertion site, and suppressor mutations partially or completely restore transcript accumulation. Studies of suppression by $\operatorname{su}(\mathrm{Hw})$ and $s u\left(w^{a}\right)$ indicate that the suppressor genes encode regulators of mobile-element transcription and RNA processing, respectively $(25,39,46)$.

The vermilion gene, located on the $X$ chromosome, is required for brown eye pigment synthesis in $D$. melanogaster, the normal eye color being a composite of red and brown pigments. We cloned the gene by P-element transposon

\footnotetext{
* Corresponding author.
}

tagging (36), and the same sequences were cloned independently by Walker et al. (43). In using a mammalian tryptophan oxygenase cDNA probe to identify clones of the $D$. melanogaster $v$ gene, Walker et al. (43) verified that $v$ encodes tryptophan oxygenase, the enzyme that catalyzes the first step in the brown-pigment biosynthetic pathway (reviewed in reference 26). Mutations at $v$ are clustered in a 2-kilobase $(\mathrm{kb})$ region, and the $v$ transcript is a 1.4-kb mRNA of relatively low abundance $(36,43)$.

Three $v$ mutations, $v^{1}, v^{2}$, and $v^{\mathbf{k}}$, can be suppressed by $s u(s)$. These alleles produce a leaky mutant phenotype and undetectable levels of tryptophan oxygenase (41). In $D$. melanogaster strains with a mutation at $s u(s)$ and with the 1 , 2 , or $\mathrm{k}$ mutation at $v$, tryptophan oxygenase activity is increased to 10 to $20 \%$ of the wild-type level (41), an amount sufficient to restore a wild-type phenotype. After the gene was cloned, the suppressible $v$ alleles were shown to be insertions of the $7.5-\mathrm{kb}$ retrotransposon 412 in the vicinity of the vermilion transcription unit $(36,43)$. Using $v$ as a model system, we are investigating the mechanism of suppression by $\operatorname{su}(s)$. Thus, we have characterized the structure of the gene in greater detail and localized the positions of all the suppressible and several unsuppressible mutations relative to introns and exons. In addition, we have examined the effects of these mutations on the transcription of $v$.

\section{MATERIALS AND METHODS}

Isolation and sequencing of clones. The mutants used in this study have been described previously $(16,36,37)$. The cloning of $v$ sequences from wild-type and mutant strains $v^{\mathrm{H} 2 \mathrm{a}}, v^{36 \mathrm{f}}, v^{\mathrm{k}}$, and $v^{2}$ was previously reported $(36)$, and genomic clones containing the $v^{48 a}$ and $v^{1}$ mutations were isolated by a similar approach. For $v^{1}, B a m H I$ rather than MboI partial fragments were cloned. Restriction maps of representative mutant clones are shown in Fig. 1. The sequence of a 3-kb region of $v^{+}$DNA between the EcoRI site (Fig. 1, coordinate 0 ) and the HindIII site (coordinate +3.0 ) 


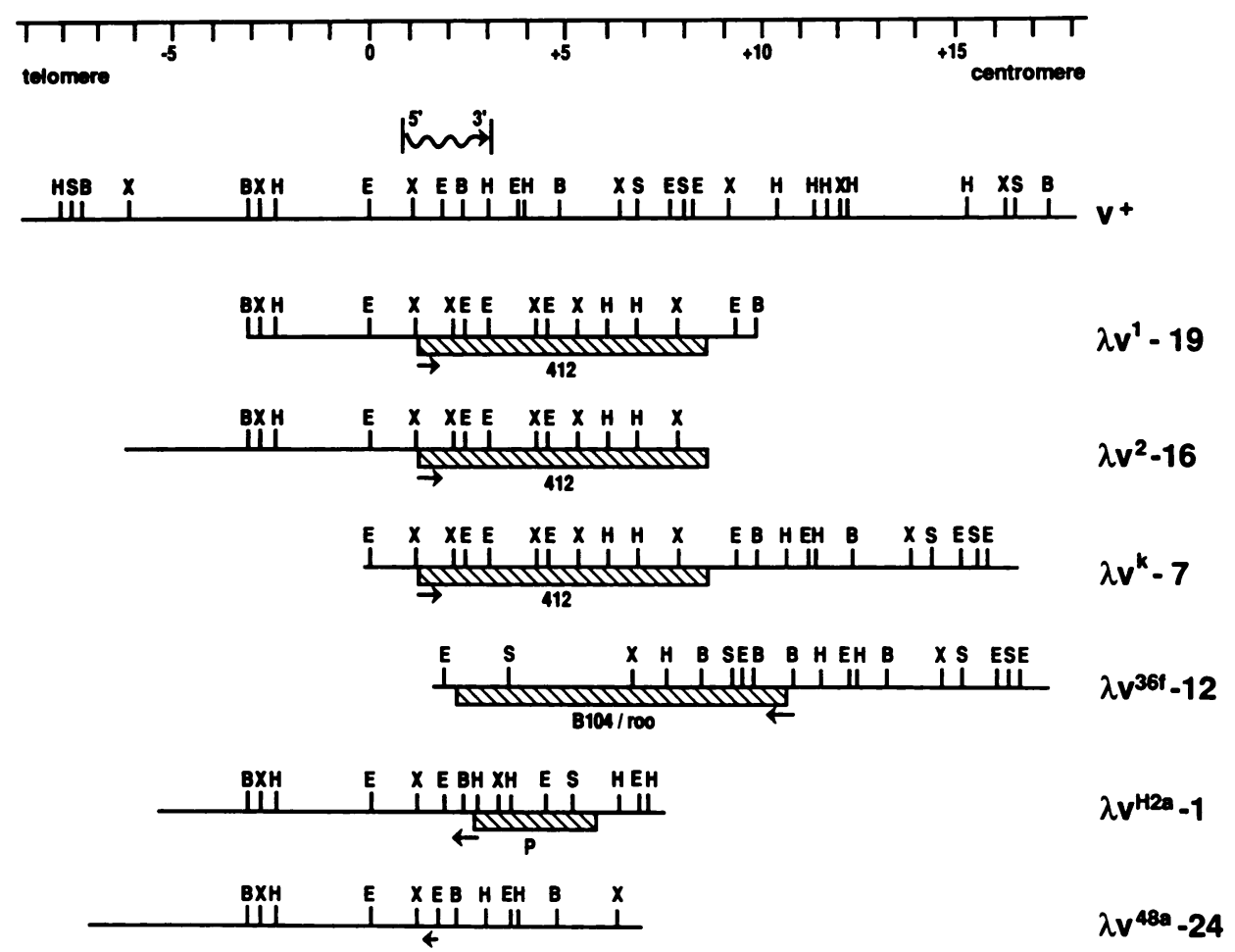

FIG. 1. Restriction maps of mutant $v$ DNA clones. The mutant clones are aligned with the wild-type $\left(v^{+}\right)$map at coordinate 0 . Restriction enzyme abbreviations: E, EcoRI; B, BamHI; H, HindIII; S, SalI; X, Xhol. Symbols: $\leadsto$, transcribed sequences; $\rightarrow$, $\leftarrow$, direction of

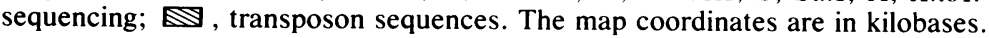

was obtained in the following manner. The $1.1-\mathrm{kb}$ EcoRIXhoI fragment (coordinates 0 to +1.1 ) and the $1.9-\mathrm{kb}$ XhoIHindIII fragment (coordinates +1.1 to +3.0$)$ from $\lambda v^{+} 8(36)$ were cloned into both M13mp18 and M13mp19 as described previously (3). A set of overlapping deletions was generated from each M13 clone by using the procedure described by Dale et al. (10), and a series of deleted clones was sequenced (32) (Fig. 2). The sequences were aligned and compiled by using the programs of Staden (40).

Mutant DNA fragments were subcloned into M13mp18 or M13mp19 and sequenced from appropriate restriction sites (Fig. 1). Sequences of the insertion mutant alleles were compared with published sequences of the transposable elements $(21,33,44)$. Since the direction of transcription has been determined for 412 (45), B104/roo (33), and P elements (21), the transcriptional orientation of each element was deduced from the restriction maps.

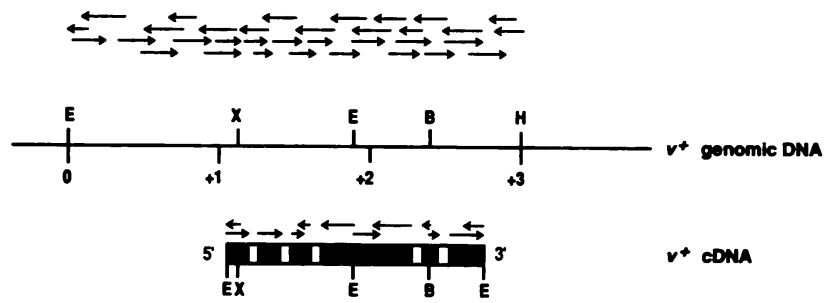

FIG. 2. Strategy for sequencing $v^{+}$genomic and cDNA clones. Symbols: $\rightarrow, \leftarrow$, direction and extent of sequencing, $\square$, exons found in the cDNA clones; $\square$, intron sequences absent from cDNA clones. Restriction enzyme abbreviations: E, EcoRI; X, XhoI; B, BamHI; $\mathrm{H}$, HindIII. Map coordinates are represented by numbers beneath the genomic DNA map.
Wild-type $v$ cDNA clones were isolated from the lateembryo, larval, and adult cDNA libraries of Poole et al. (28). The libraries were screened as described previously (35) by using the 1.9-kb XhoI-HindIII fragment (coordinates +1.1 to $+3.0)$. The largest cDNAs were purified from the F2 (12- to 24-h embryo) and G2 (first- and second-instar) libraries. Fragments of cDNA were transferred to M13 vectors and sequenced (Fig. 2).

Determining the direction of transcription. The $1.9-\mathrm{kb}$ EcoRI A fragment (Fig. 1, coordinates 0 to +1.9 ) and the 1.9-kb EcoRI B fragment (coordinates +1.9 to +3.8 ) were subcloned from $\lambda v^{+} 8$ into M13mp10. By restriction analysis of double-stranded replicative-form DNA, the orientation of $v$ DNA in the M13 vector was determined. One orientation results in the production of the $v$ transcribed strand as single-stranded DNA, whereas the other orientation produces the $v$ nontranscribed strand in the single-stranded form. Single-stranded M13 DNAs containing transcribedand nontranscribed-strand sequences were hybridized separately to Northern (RNA) blots containing $20 \mu \mathrm{g}$ of poly(A) ${ }^{+}$ RNA from adult flies. Hybrids were detected after a second hybridization with ${ }^{32} \mathrm{P}$-labeled M13mp10 DNA synthesized with a universal sequencing primer as described by Kuroiwa et al. (14).

Northern analysis. Adult poly $(\mathrm{A})^{+}$RNA $(20 \mu \mathrm{g})$ was fractionated on formaldehyde-agarose gels (9) and transferred to nitrocellulose or nylon membranes (42). The hybridizations and washes were performed as described by O'Hare et al. (20). Plasmid probes were labeled with ${ }^{32} \mathrm{P}$ by nick translation (17).

Exon mapping. Fragments of $v$ genomic DNA and $v$ cDNA F2-2 were subcloned into either pGEM-1 or pGEM-7Zf (Promega Biotec). Antisense RNA probes (riboprobes) were 
synthesized from linearized plasmid templates with SP6 or T7 RNA polymerase and 50 to $200 \mu \mathrm{Ci}$ of [ $\left.{ }^{32} \mathrm{P}\right] \mathrm{CTP}(800$ $\mathrm{Ci} / \mathrm{mmol}$ ) as described by Melton et al. (18). For the hybridization reaction, 5 to $20 \mu \mathrm{g}$ of poly(A) ${ }^{+}$RNA and $1 \times 10^{6}$ to $5 \times 10^{6} \mathrm{cpm}$ of probe were mixed in hybridization buffer (18) and incubated at $85^{\circ} \mathrm{C}$ for $5 \mathrm{~min}$ and then at $42^{\circ} \mathrm{C}$ overnight. In some experiments hybrids were digested with RNase (18). In other instances hybrids were purified over small oligo(dT)-cellulose columns to reduce background, as described by Chou et al. (8), and then samples were treated with $\mathrm{S} 1$ nuclease by the procedure of Quarless and Heinrich (30). Protected fragments were resolved by electrophoresis on an 8 to $15 \%$ polyacrylamide-7 $\mathrm{M}$ urea sequencing gel. Sequencing reactions of M13mp18 DNA with the universal primer and Sequenase (U.S. Biochemical Corp.) were run in parallel lanes to provide size standards.

Primer extension analysis. Two synthetic oligonucleotides were used in these experiments: 5'-TCCGTTTCCTGCAT AGGG-3' (oligo 1235) and 5'-GCCCACTTCCGTGGTTAA TGGCACCGCCG-3' (oligo 1489). The oligonucleotides were labeled with ${ }^{32} \mathrm{P}$ at the $5^{\prime}$ ends by using polynucleotide kinase (17). The labeled oligonucleotides were purified by electrophoresis on a $15 \%$ polyacrylamide gel. They were eluted from the gel slice by overnight incubation at $37^{\circ} \mathrm{C}$ in 0.3 to $0.5 \mathrm{ml}$ of TE (10 mM Tris hydrochloride [pH 8.0], 1 mM EDTA). The oligomer in TE was extracted sequentially with equal volumes of phenol, phenol-chloroform, and chloroform before ethanol precipitation. Primer extension experiments were performed as described by Calzone et al. (6), with the following modifications. The annealing reaction mixture contained $20 \mu \mathrm{g}$ of poly $(\mathrm{A})^{+}$RNA or tRNA (in control reactions) and approximately $0.3 \mathrm{pmol}\left(10^{5}\right.$ to $10^{6}$ $\mathrm{cpm}$ ) of end-labeled oligonucleotide primer in $30 \mu \mathrm{l}$ of hybridization solution (6). This mixture was incubated at $85^{\circ} \mathrm{C}$ for $5 \mathrm{~min}$ and then at $42^{\circ} \mathrm{C}$ for $1 \mathrm{~h}$. To the annealing reaction were added $4 \mu$ l of $10 \times$ reverse transcriptase buffer (6), $5 \mu \mathrm{l}$ of a $20 \mathrm{mM}$ deoxynucleoside triphosphate solution ( $5 \mathrm{mM}$ in each of the four deoxynucleotide triphosphates), 1 $\mu \mathrm{l}(40 \mathrm{U})$ of RNasin, and $0.5 \mu \mathrm{l}(16 \mathrm{U})$ of avian myeloblastosis virus reverse transcriptase (XL grade; Life Sciences). The reaction mixture was incubated at $42^{\circ} \mathrm{C}$ for $1 \mathrm{~h}$, and after phenol extraction and ethanol precipitation the reaction products were applied to an $8 \%$ acrylamide-7 $\mathrm{M}$ urea sequencing gel. The sizes of the extended products were determined by using sequencing reactions of M13mp18 DNA in parallel lanes.

Nucleic acid isolation. Plasmid and lambda DNAs were purified by standard procedures (17). Single-stranded M13 DNA was isolated as described in the Amersham Corp. sequencing handbook. RNA was, in most cases, prepared as described previously (3) by homogenization in sodium dodecyl sulfate-urea buffer, repeated phenol extractions, and purification on oligo(dT)-cellulose. For use in the primer extension experiments, RNA was isolated by homogenization in guanidine thiocyanate followed by lithium chloride precipitation (2) and purification on oligo(dT)-cellulose. Wild-type $\left(v^{+}\right)$RNA was isolated from either an Oregon R or $y^{2} w^{\text {bf }}$ strain.

\section{RESULTS}

Localization of the $v$ transcription unit. We previously reported (36) that the 1.4-kb $v$ transcript hybridized to two adjacent 1.9-kb EcoRI fragments (Fig. 1, coordinates 0 to +1.9 and +1.9 to +3.8$)$. From Northern analysis with smaller fragments as probes, we subsequently determined that most if not all $v$ transcribed sequences were found between the XhoI and HindIII sites (coordinates +1.1 to +3.0). The 1.1-kb EcoRI-XhoI fragment (coordinates 0 to +1.1 ) did not produce a detectable signal when it was hybridized to wild-type RNA (data not shown). To determine the direction of transcription, we probed Northern blots of poly $(\mathrm{A})^{+}$RNA with single-stranded M13 clones of $v$ fragments from this region (see Materials and Methods). These experiments demonstrated that the direction of transcription is from left to right (Fig. 1). This conclusion was subsequently verified by analysis of cDNA clones (see below).

Structure of the $v$ transcription unit. The intron-exon structure of the $v$ gene was determined by comparing the sequences of genomic and cDNA clones and by RNA protection experiments. We sequenced a $3-\mathrm{kb}$ region of $v^{+}$ genomic DNA extending from the EcoRI site at coordinate 0 to the HindIII site at coordinate +3.0. In addition, we isolated and sequenced $v$ cDNA clones from the libraries of Poole et al. (28). Approximately $20 v$ cDNA clones were isolated, and since EcoRI linkers were added to the cDNAs during the cloning process (Fig. 2), the sizes of the cDNAs were estimated by examining the EcoRI digestion pattern. One of the largest cDNA clones, G2-4, isolated from a firstand second-instar library, was sequenced from convenient restriction sites (Fig. 2), and the sequence was compared with the genomic sequence (Fig. 3). The cDNA sequences align with genomic sequences between nucleotides (nt) 1046 and 2775 . Within this region are six exons of the $v$ gene, a 5' exon of at least $152 \mathrm{nt}$, and five additional exons (ordered 5' to $3^{\prime}$ ) of $161,134,607,94$, and $227 \mathrm{nt}$. As will be discussed below, the first exon in this cDNA extends further 5' than most $v$ mRNAs. The intervening sequences are quite small, ranging from 54 to $91 \mathrm{nt}$. An open reading frame begins in the first exon at nt 1172. The sequence GCACCATG (nt 1167 to 1174) at the presumptive initiation site matches the consensus for a eucaryotic translation start site, CC(A/G)CCATG (12), at seven of eight positions. Upon splicing, this open reading frame extends to nt 2665 and would generate a 380 -amino-acid polypeptide of predicted molecular mass 44.4 kilodaltons. This approximately corresponds to the expected monomer molecular mass of tryptophan oxygenase $(1,36)$. The polyadenylation signal AATAAA (29) is found beginning at nt 2742 , approximately $30 \mathrm{nt}$ upstream of the $3^{\prime}$ end of the cDNA.

Mapping the 5' end of the $v$ RNA. S1 nuclease protection experiments were performed to define the $5^{\prime}$ exon of $v$. A 1.9-kb XhoI-HindIII fragment (Fig. 4, probe a) protects most $v$ exons except sequences upstream of the XhoI site (Fig. $4 \mathrm{~A}$, lane 2 ), and the sizes of the protected fragments observed are consistent with the cDNA sequence analysis. A probe which covers the entire $5^{\prime}$ half of $v$ transcribed sequences (Fig. 4, probe b) generated all of the expected protected fragments except the one expected to be larger than 152 nt. Instead, we observed an 83-nt exon (Fig. 4B, lane 5). Probe $\mathrm{c}$, which includes $5^{\prime}$ sequences extending to the XhoI site, protects 60 of the 83 nt (Fig. 4B, lane 6). Furthermore, no protected fragments were detected with probes which included sequences between the XhoI site in the $5^{\prime}$ region to the upstream EcoRI site (data not shown). Thus, we concluded that the $5^{\prime}$ exon is $83 \mathrm{nt}$ and spans the $X$ hoI site, with $60 \mathrm{nt}$ downstream and $23 \mathrm{nt}$ upstream of the $X h o I$ site. This analysis places the transcription start site at nt 1115 (Fig. 3).

S1 mapping experiments with cDNA probes confirmed the results obtained with genomic probes. The $295 \mathrm{nt}$ of $v$ cDNA 
GAATTCCAAGCACATTGCAAGAATCCCAAATCAAAAAATCGCATGAAATTGCCCCCGTACCTTTTGCGTTTTACTCCCAGATGTAACTCA ATTTTTTCTATGCAAAAGTAGTTGAAAATTATATAATAAAAACCGATTAGAAAAACAAAACATACATATATATATATATAAATATATATA AAACCAACAACAGAAAATGTGTAAGAAATAGTATAAATAAGGTCGGATATTAATGCCCCGACATTACGCTATATGTATGTGCTGGGGCAA ACAGCAACAAATCCAATAAAACAAAGTAATTAACAACAAACAAAACGGATGAAACAACCAAGATTATGTAAGCGATGGATCGAAGTAAGA ATTGATGCGAACGGCACAAGTATATAACAAATTTCAACAAGTATATGACTGAGCCAATGACTCAAAAATACATTTTAAATAAAAGGGAAA ACCAGAAATATATGAAAAATATAAAAACGATAAGCAAGTGAATGAAAGCTCTTTTTCTTTTTTGGGTTTTGGGAACTGCAAATTATTGAT TGTATGGAAATGTTTGTTTACCTATTTTTGCATATGGTGCGATTGTATCAAAACAAGTTTTGAATTATCAAAATTGGTTCCATTTATTTT TATACAACCTTGACCTATTTTCAAGGACCAATAAGATTGGACCCCACATTAACTTAGAAAACAATACTTGCCATGTTCAATTTTATTCCT ACGCAGGGTTTATTTATTATTATACTATGTTAATCAAAAAATTAAAATGTTAATTTCTCAGTTATTTAACTACACCTTAGGTAACTCTGA TTTGGCATTTCTCACTGAACTGTACTACTGTAGACTACCTTCCATTCAGGAAAATATTTGTGTGCGCCGCACTTTCACCTCAAGTGATTG

$$
\begin{aligned}
& 1 \mathrm{G2}-4 \\
& \text { \$F2-2 }
\end{aligned}
$$

ATAATTCCCAGCCTATCTGGCAGTGCCCATCGCCCAGATCACCGACTGTGCAATCAGTCGGAACTGGAGCTCTCTCGCTCTGTTATCGGT $+1 \quad \$ 62-7$

$\nabla \mathbf{1 , 2 , k}$

1081 TCGCTGGGGTCTCATCTCCGGTCCGCTGGCGGAGATCAGTTCGCCAGCATCCGCCGCTCGAGGAGTCACGATCTGATCTGAGCTGTGCAC

1171 CATGAGCTGTCCCTATGCAGGAAACGgGTGAGCACCAGCACGTGCTGTCCAGGAATGCCAATCGATCTTCAGTTCTGCGATTCAATTCAA MetSerCysprotyralaglyAsngl

1261 ACCCATACAGAAACGATCACGATGATTCGgCGgTGCCATTAACCACGGAAGTGGGCAAAATCTATGGAGAGTATCTGATGCTGGACAAAC YAsnAspHisAspAspSerAlaValProLeuThrThrGluValGlyLysIleTyrGlyGluTyrLeuMetLeuAspLysL

1351 TGCTGGATGCCCAGTGTATGCTGTCCGAGGAGGACAAGCGACCCGTGCACGATGAGCATCTGTTCATCATCACGCACCAGGGTGAGTAGG euLeuAspAlaGlnCysMet LeuSerGluGluAsplysArgProValHisAspGluHis LeuPheIleIleThrHisGlnA

1441 TTTACAACTTTGATGACAACACTCAATGGCATTTAAGTACCTTCGCCACAGCCTACGAGCTTTGGTTCAAGCAGATCATCTTTGAGTTCG laTyrGluLeuTrPPheLysGlnIleIlePheGluPheA [48a

1531 ACTCCATACGAGACATGTTGGATGCAGAGGTCATCGATGAAACCAAGACGCTGGAGATTGTCAAGCGACTGAACCGAGTGGTTCTGATTC spSerIleArgAspMet LeuAspAlaGluValI leAspGluThrLysThrLeuGluI leValLysArgLeuAsnArgValValLeuIleL

1621 TAAAAGTGAGTGCTTTCTGAATCTCTTACCAAAATCCGTTTATAACTTCCTTTGTACAGCTCCTGGTGGACCAAGTGCCCATTCTGGAGA eulys LeuLeuValAspGinValproIleLeugluT

1711 CCATGACCCCGTAGACTTCATGGACTTCCGCAAGTACCTGGCACCCGCATCTGGTTTTCAGTCGCTGCAGTTCCGTTTGATCGAGAACA hrMet ThrProLeuAspPheMetAspPheArgLys TyrLeuAlaProAlaSerGlyPheGlnSerLeuGlnPheArgLeuI leGluAsnL 48]

1801 AGCTGgGAGTTCTGACAGAGCAGCGgGTGAGATACAACCAGAAGTACTCGgATGTCTTTAGCGACGAGGAGgCGCGGAATTCGATTCGCA ysLeuGlyValLeuThrGluGInArgValArgTyrAsnGlnLysTyrSerAspValPheSerAspGluGluAlaArgAsnSerIleArgA

1891 ACTCGGAGAAAGATCCCTCGCTACTGGAGCTAGTGCAGCGATGGCTGGAGAGGACGCCCGGACTGGAGGAGAGTGGCTTCAACTTCTGGG snSerGluLysAspProSerLeuLeuGluLeuValGlnArgTrpLeuGluArgThrProGlyLeuGluGluSerGlyPheAsnPheTrPA

1981 CCAAGTTTCAGGAGAGCGTCGATCGATTCCTGGAGGCGCAGGTACAGAGCGCCATGGAGGAGCCCGTGGAGAAGGCGAAAAACTACCGCC laLysPheGInGluSerValAspArgPheLeuGluAlaGlnValGInSerAlaMetGluGluProValGluLysAlaLysAsnTyrArgL

2071 TCATGGACATTGAGAAGCGACGCGAGGTGTATCGCTCCATCTTTGATCCGGCAGTGCACGATGCACTGGTGCGTCGTGGGGATCGCCGGT euMetAspI leGluLysArgArgGluValTyrArgSerI lePheAspProAlaValHisAspAlaLeuValArgArgGlyAspArgArgP

2161 TTAGCCATCGTGCCCTTCAGGGAGCCATCATGATCACCTTCTATAGGGATGAACCCAGGTTCAGCCAACCACACCAGTTGCTCACCCTGC heSerHisArgAlaLeuGlnGlyAlaIleMetIleThrPheTyrArgAspGluProArgPheSerGlnProHisGlnLeuLeuThrLeuL $\nabla 36 \mathbf{f}$

2251 TCATGGACATCGACTCGTTAATAACCAAGTGGAGATGTAAGTATTGCATTCTTTGATACTCTTTTATAAATATATCTTATGTTTAAGACT euMetAspIleAspSerLeuIleThrLysTrpArgT

2341 GGTTTTCCTAACCAAATACTTTCTATTCCCGCCGCAGACAATCACGTGATCATGGTGCAACGCATGATTGGATCCCAACAGTTGGGCACT yrAsnHisVali leMetValglnArgMet IleGlySerGlnGlnLeuGlyThr

2431 GGTGGCTCGTCTGGATATCAATATCTGCGCTCCACTCTCAGGTGATCATCGCAGATGTGATTATATCGGGGATCAATGAACTCAAACTGT GlyGlySerSerGlyTyrGlnTyrLeuArgSerThrLeuSe

2521 TCTCCCTTTGTTTTTTTTGGTTTCAGTGATCGGTACAAGGTGTTTCTGGATCTGTTCAATCTGTCCACTTTTCTGATTCCCCGCGAGGC rAspArgTyrLysVal Phe LeuAspLeuPheAsnLeuSerThrPheLeuI leProArgGluAl $\nabla$ H2a

2611 GATTCCACCGCTGGACGAGACCATTCGCAAGAAACTGATCAACAAAAGTGTCTGACAATCGGCAGGGTATCCAATTGGTCAATGTTTGGC aI leProproLeuAspGIUThrI leArgLysLys LeuI leAsnLys SerValEnd

2701 TATGCGTTGTTTGTTCTGCCTACTGTTTTGTCGTTTTGGTGTAATAAAATTACTTGTTTAGTCTTTGTTATCACATTTGATGTGTTCCTT

2791 TTCTTTATGTCTGACATATAATACATATAACATAACAAAATAAATATTCATATTTCAGACATAAACAAATTCTATGGGAATGTGTGAGTC 2881 AGCAGCCTGAAAGTAGACCATATATATTCTGGTTGTCTTTCTCGCTCGTTTCTATTAGTTCGTTAGCAAATTAAATTCCATAATATTGTG

2971 TGGCAATACTTGTCAAAATAATAATGGTATAAGTGAATTTTAATTACAAAATACCGATTTAAACAAAAAGCTT

FIG. 3. Sequence of the $v$ gene. The genomic sequence from the EcoRI site (coordinate 0 in Fig. 2) to the $H i n d I I I$ site (coordinate +3.0 in Fig. 2) is shown. The following restriction sites are underlined: EcoRI, nt 1 to 6 and nt 1877 to $1882 ; X$ hoI, nt 1137 to $1142 ; B a m H I$, nt 2310 to 2315 ; and HindIII, nt 3038 to 3043 . Symbols: $\downarrow, 5^{\prime}$ ends of the longest cDNA clones; $\$, 3^{\prime}$ end of one cDNA, $\nabla$, transposon insertion sites. The boundaries of the deletion mutation are indicated by brackets above the relevant sequences. The major transcription start site $(+1)$ was deduced by $\mathrm{S} 1$ and primer extension analyses. Splice sites are indicated by interruptions of the translational reading frame. 


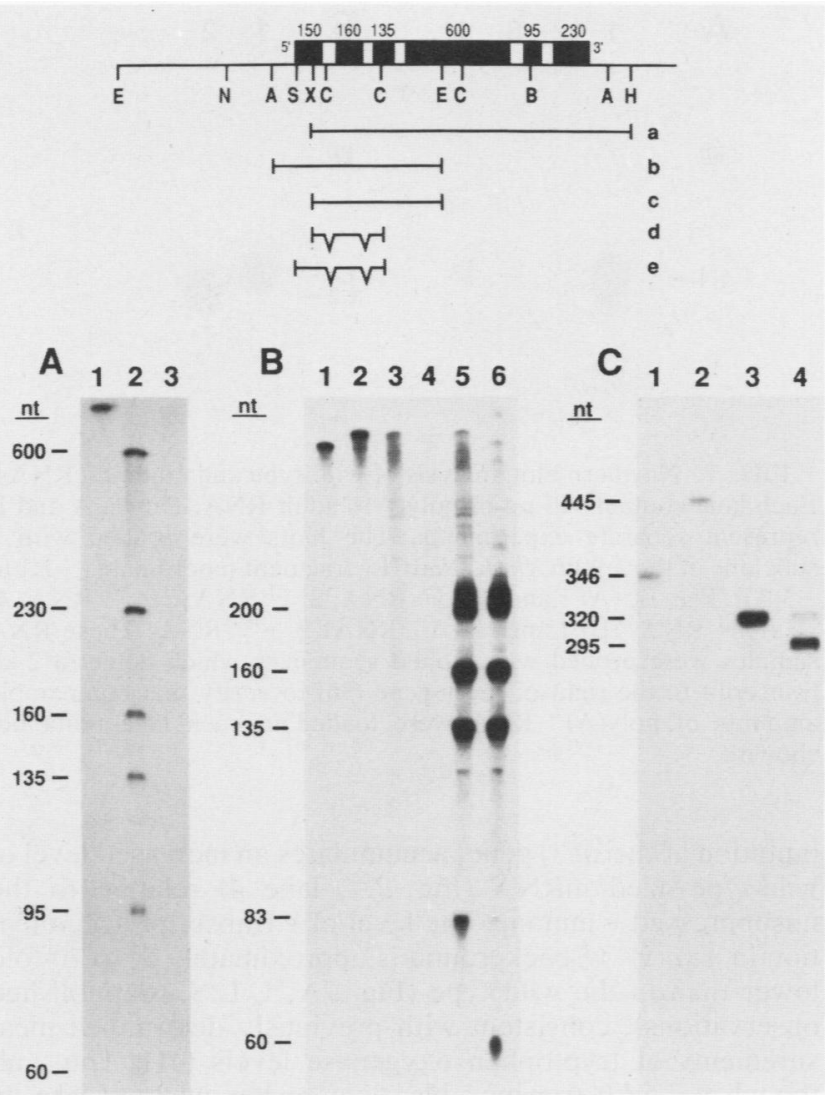

FIG. 4. S1 protection analysis of $v^{+}$exons. The exon lengths indicated above the solid bars in the map are approximations based on the cDNA sequence. Probes $\mathrm{a}, \mathrm{b}$, and $\mathrm{c}$ are derived from genomic clones, whereas probes $\mathrm{d}$ and $\mathrm{e}$ are derived from cDNA clones. Restriction enzyme abbreviations: A, AccI; B, BamHI; C, ClaI, E, EcoRI; H, HindIII; N, NdeI; S, SacI; X, XhoI. In lanes containing probe alone there was no $S 1$ treatment. In the experimental lanes (probe plus RNA), wild-type poly(A) ${ }^{+}$RNA from second-instar larvae was annealed to radioactively labeled antisense RNA probes and subsequently treated with S1 nuclease. In the no-RNA controls, probe was incubated with tRNA and subsequently treated with S1 nuclease. Panels $A$ to $C$ represent separate experiments. (A) Lanes: 1, probe a; 2, probe a plus RNA; 3, probe a, no-RNA control. (B) Lanes: 1 , probe $c ; 2$, probe $b ; 3$, probe $b$, no-RNA control; 4 , probe c, no-RNA control; 5 , probe b plus RNA; 6 , probe c plus RNA. (C) Lanes: 1 , probe d; 2 , probe e; 3 , probe e plus RNA; 4 , probe d plus RNA. No bands were detected in the no-RNA controls for the experiment in panel C (data not shown). The faint band at 320-nt in lane $4 \mathrm{C}$ was caused by slight contamination with probe $\mathrm{e}$.

sequences between the $C l a \mathrm{I}$ and $X h o I$ sites were completely protected when annealed to wild-type RNA (Fig. 4C, lane 4). However, only 25 additional nucleotides of cDNA sequences upstream of the XhoI site were protected (Fig. 4C, lane 3). We did not readily detect the 374-nt fragment, which would be observed if the entire $v$ cDNA fragment had been protected. A faint band of this size was seen in longer exposures; however, we do not know whether it is a relevant product. The same $\mathrm{S} 1$ protection pattern was observed regardless of the source (i.e., developmental stage or $D$. melanogaster strain) of RNA (data not shown).

We independently mapped the transcription start site by primer extension experiments. End-labeled synthetic oligonucleotides, complementary to sequences near the $5^{\prime}$ end of $v$ RNA, were used to prime cDNA synthesis. Oligo 1235 , an

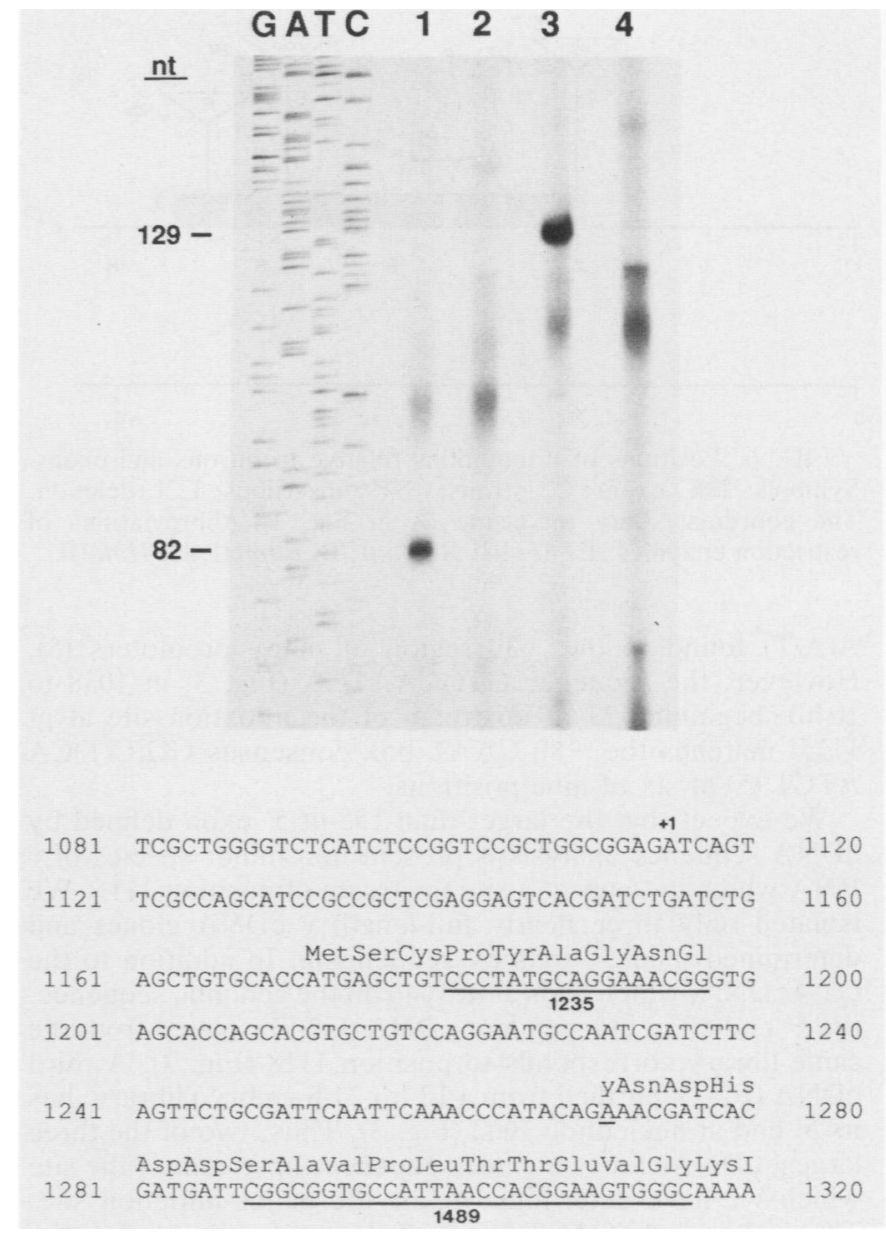

FIG. 5. Mapping the $5^{\prime}$ end the $v$ by primer extension. Endlabeled synthetic oligos 1235 and 1489, complementary to the underlined sequences, were used to prime cDNA synthesis on wildtype RNA. Lanes: 1 , oligo 1235 plus RNA; 2 , oligo 1235 plus tRNA: 3 , oligo 1489 plus RNA; 4 , oligo 1489 plus tRNA. The lengths of the extension products are indicated. M13mp18 DNA was sequenced by using the universal primer and used as the size standards. The major transcription start site $(+1)$ is indicated on the DNA sequence.

18-mer which anneals to $17 \mathrm{nt}$ in exon 1 and $1 \mathrm{nt}$ in exon 2 (Fig. 5, nt 1181 to 1197 and nt 1271, respectively), primed the synthesis of an 82-nt extension product (Fig. 5, lane 1), which places the $5^{\prime}$ end of the RNA at the $\mathrm{C}$ residue at position 1117 (Fig. 3 and 5). Oligo 1489, a 29-mer which anneals to exon 2 sequences (Fig. 5, nt 1288 to 1316), generated a 129-nt extension product (Fig. 5, lane 3), placing the 5' end at nt 1115 (Fig. 3 and 5).

Thus, both primer extension and $\mathrm{S} 1$ mapping experiments place the $5^{\prime}$ end of the $v$ RNA at approximately the same site. Within this region is found the heptanucleotide sequence ATCAGTT (Fig. 3 and 5, nt 1115 to 1121), which perfectly matches the consensus sequence ATCA(G/T)T $(\mathrm{C} / \mathrm{T})$ which is found at the transcription initiation sites of a number of $D$. melanogaster genes (11) and which is thought to be important for capping. On the basis of primer extension and $\mathrm{S} 1$ analysis, we have designated the $\mathrm{A}$ residue at nt 1115 (Fig. 3 and 5) as the major $v$ initiation site. Transcription of other D. melanogaster genes is most frequently found to start at that position within the heptanucleotide consensus. Upstream of the initiation site at nt 1115 there are no sequences similar to the TATA box consensus TATA(A/T) 


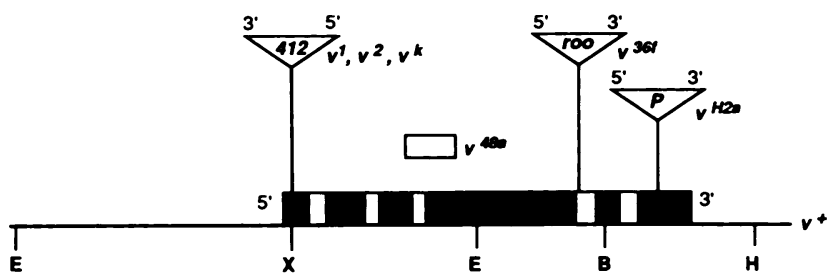

\begin{tabular}{llll}
\hline+1 & +2 & +3
\end{tabular}

FIG. 6. Positions of $v$ mutations relative to introns and exons. Symbols: $\square$. exons: Z, introns: $\nabla$. insertions: $\square$. deletion. The coordinates are the same as in Fig. 1. Abbreviations of restriction enzymes: E, EcoRI: X. Xhol: B. BamHI; H. HindIII.

$A(A / T)$ found in the -30 region of many promoters (5). However, the sequence GTGCAATCA (Fig. 3, nt 1038 to 1046), beginning $77 \mathrm{nt}$ upstream of the initiation site at $\mathrm{nt}$ 1115 , matches the -80 CAAT box consensus $\mathrm{GG}(\mathrm{C} / \mathrm{T}) \mathrm{CA}$ ATCT (5) at six of nine positions.

We expect that the larger-than-152-nt $5^{\prime}$ exon defined by cDNA sequence analysis is present in a minor species of $v$, RNA which initiates at a site upstream of position 1115 . We isolated only three nearly full-length $v$ cDNA clones and determined their 5 ' ends by sequencing. In addition to the G2-4 cDNA, which ends at nt 1046 on the genomic sequence, the $5^{\prime}$ end of an independent cDNA (G2-7) isolated from the same library corresponds to position 1118 (Fig. 3). A third cDNA (F2-2), purified from a 12- to 24-h embryo library, has its $5^{\prime}$ end at nucleotide 1062 (Fig. 3). Thus, two of the three largest cDNA clones include sequences upstream of the site which we have determined to be the major initiation site. The sequence ATCAGTC, which also perfectly matches the heptanucleotide consensus sequence, is found in the region where the largest cDNA clone ends (Fig. 3, nt 1043 to 1049). If transcription initiates at the A residue at position 1043, the $5^{\prime}$ exon of this minor $v$ RNA species would be $155 \mathrm{nt}$. However, since we have not detected these $5^{\prime}$ sequences in $\mathrm{S} 1$ or primer extension experiments, initiation at this position has not been verified. There are no potential TATA or CAAT boxes upstream of the possible minor transcription start site at position 1043 .

Analysis of the 412 insertions. The $v^{1}, v^{2}$, and $v^{\mathrm{k}}$ mutations differ from other $v$ alleles in that they are both leaky and suppressible by the suppressor of sable. Each of these mutations is associated with a 412 insertion in the $5^{\prime}$ gene region (Fig. 1). We cloned $v$ DNA from the three mutants (Fig. 1) and localized the positions of mutations by DNA sequencing. The 412 element is located at the same position, between nt 1150 and 1151, in all three mutations (Fig. 3). This insertion site is within exon 1,36 nt downstream of the major transcription start site and $21 \mathrm{nt}$ upstream of the translation initiation site (Fig. 3 and 6). On the basis of the restriction map of the $v 412$ insertion mutants (Fig. 1) and the sequence data, we determined that the 412 element in each mutant is oriented such that it would be transcribed in the opposite direction to $v$ (Fig. 6). Northern blot analysis showed that, as reported previously (36), the level of $v$ RNA is drastically reduced in the 412 insertion mutant $v^{1}$. However, a faint, wild-type-sized band is consistently observed (Fig. 7A, lane 2). Similarly, reduced levels of transcript are apparent in $v^{2}$ and $v^{\mathrm{k}}$ mutants (data not shown). The $\operatorname{su}(s)^{2} v^{1}$ mutant, which has a 412 insertion mutation at $r$ and a

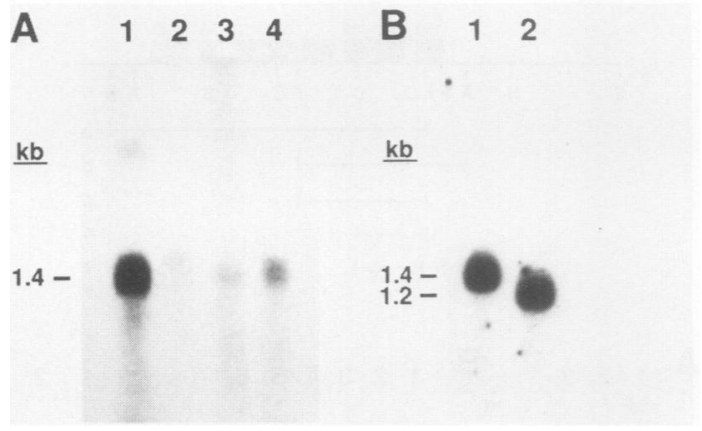

FIG. 7. Northern blot analysis of wild-type and mutant $v$ RNAs. Each lane contains $20 \mu \mathrm{g}$ of poly $(\mathrm{A})^{+}$adult RNA. Panels A and B represent separate experiments. The blots were probed with a subclone of the 1.9-kb Xhol-HindIII $v$ fragment (coordinates +1.1 to +3.0 in Fig. 1). (A) Lanes: $1, v^{+}$RNA; $2, v^{1}$ RNA; 3, $v^{36 f}$ RNA; 4 , $s u(s)^{2} v^{1}$ RNA. (B) Lanes: $1, v^{+}$RNA; $2, v^{48 a}$ RNA. These RNA samples were probed with cloned sequences which detect a 2-kb transcript to the right of the $v$ gene (36) to verify that comparable amounts of poly $(A)^{+}$RNA were loaded in each lane (data not shown).

mutation at the $s u(s)$ gene, accumulates an increased level of wild-type-sized mRNA (Fig. 7A, lane 4) relative to the unsuppressed $v$ mutant. The level of $v$ transcript accumulation in a $s u(s)^{2},{ }^{1}$ background is approximately 5- to 10 -fold lower than in the wild type (Fig. 7A; L.L.S., unpublished observations), consistent with previously determined measurements of tryptophan oxygenase levels (41). Thus, although a 7.5-kb transposable element has inserted into an exon, the mature RNA is the same size as in the wild type. A more detailed analysis of the $v$ RNA produced in the presence of the suppressor is currently in progress.

Analysis of other $v$ alleles. We had previously determined that the $v^{48 \text { a }}$ allele has a 200 -nt deletion in the $v$ gene between the $X h o l$ and EcoRI sites (Fig. 1, coordinates +1.1 and +1.9 ). Northern analysis showed that the $v^{48 a}$ mutant accumulates the same level of RNA as a wild-type strain (Fig. 7, lane 2), and, as expected, the RNA is slightly smaller than the wild-type $v$ transcript. When $\operatorname{poly}(\mathrm{A})^{+}$RNA from the $r^{48 \text { a }}$ mutant was hybridized to wild-type sequences between the Xhol and HindIII sites (probe a) and subsequently treated with RNase, the 600- and 135-nt protected $v^{+}$fragments were not detected, and new fragments, approximately 480 and $110 \mathrm{nt}$, were observed instead (Fig. 8A, lane 3). The region of the 600-nt exon affected is the portion which lies upstream rather than downstream of the $E c \circ$ RI site (Fig. 8A, lanes 6 and 9). Sequence analysis of cloned $v^{48 a}$ DNA revealed that sequences between nt 1599 and 1802 (Fig. 3) are deleted in this mutant. Interestingly, the deletion does not alter the translational reading frame (Fig. 3); thus, a mutant polypeptide consisting of 50 fewer amino acids might be synthesized from this mutant gene.

The $v^{36 f}$ mutant was previously shown to contain a B104/ roo insertion to the right of the 412 insertion site at $v$ (Fig. 1). The sequence of mutant DNA revealed that the insertion occurred between nt 2298 and 2299 (Fig. 3) in intron 4 of the $v$ gene, $12 \mathrm{nt}$ downstream of the splice donor site. The element is oriented such that it would be transcribed in the same direction as $v$ (Fig. 6). The $v^{, 36 f}$ mutation drastically reduces the level of $v$ transcript accumulation. A faint signal was frequently observed on Northern blots, indicating that at least some $v$ RNA accumulates which is approximately the same size as in the wild type (Fig. 7A, lane 3 ). The $v^{36 f}$ 


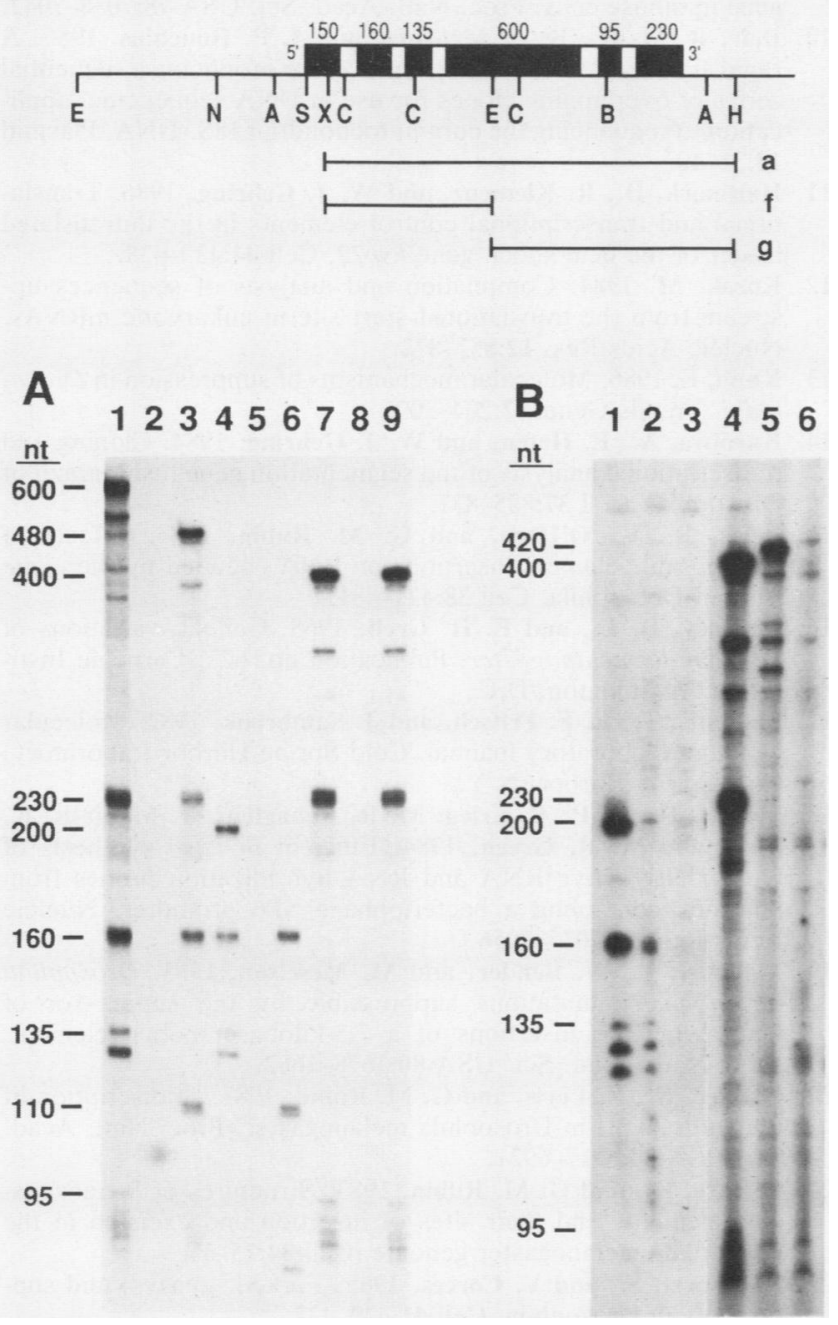

FIG. 8. RNase mapping of $v$ mutant exons. The exon lengths indicated above the solid bars on the map are approximations based on the cDNA sequence. Probes a, $f$, and $g$ are derived from genomic clones. Restriction enzyme abbreviations: E, EcoRI: N, NdeI: A. AccI; S, SacI; X. XhoI: C, ClaI; B, BamHI: H, HindIII. In these experiments, antisense RNA probes were annealed to RNA from wild-type or mutant adults, and the hybrids were treated with RNase. When RNase was used, several protected fragments appeared as doublets or triplets, owing to variable RNase cleavage at the ends. Panels $A$ and $B$ represent separate experiments. (A) Lanes: 1, probe a and $v^{+}$RNA: 2, probe a and $v^{1}$ RNA; 3, probe a and $v^{48 a}$ RNA: 4, probe f and $v^{+}$RNA; 5, probe f and $v^{1}$ RNA: 6 . probe $f$ and $v^{48 a}$ RNA; 7 , probe $g$ and $v^{+}$RNA; 8 , probe $g$ and $v^{1}$ RNA; 9, probe g and $v^{48 a}$ RNA. (B) Lanes: 1 , probe $f$ and $v^{+}$RNA: 2 , probe f and $v^{36 f}$ RNA; 3 , probe f and $v^{1}$ RNA; 4, probe $g$ and $v^{+}$ RNA; 5 , probe $g$ and $v^{36 f}$ RNA; 6 , probe $g$ and $v^{1}$ RNA. The sizes of the protected fragments are indicated.

mutant transcript is more readily detectable in RNase mapping experiments (Fig. 8B). This analysis showed that the mutant RNA contains $v$ sequences upstream of the B104/roo insertion site but lacks $v$ sequences downstream of the insertion. Exons 5 and 6 are not present in $v^{36 f}$ RNA, and a few additional nucleotides are included in exon 4 (Fig. 8B. lane 5). This result would be expected if the RNA includes intron sequences upstream of the B104/roo insertion site and terminates at a site within the element. Polyadenylation in the $5^{\prime}$ long terminal repeat of the B104/roo element would generate a mature RNA of approximately the same size as the $v^{+}$RNA. Unlike the $v^{1}, v^{2}$, and $v^{, \mathrm{k}}$ alleles, the $v^{36 \mathrm{f}}$ mutant does not exhibit a leaky phenotype and has no detectable tryptophan oxygenase activity (41). Thus, sequences downstream of the insertion site are probably needed to produce functional enzyme. The suppressor of sable has been reported to slightly elevate $v$ expression in the $36 \mathrm{f}$ mutant (41). However, this effect is not detectable by Northern analysis (data not shown).

The P-element insertion mutation, $v^{\mathrm{H} 2 \mathrm{a}}$, that was used to clone $v$ is located to the right of the B104/roo insertion site (Fig. 1). Sequence analysis revealed that the insertion is within $v$ exon 6 between nt 2626 and 2627 (Fig. 3 and 6). The 8-nt sequence adjacent to the insertion site, CGCTGGAC, matches the P-element target site consensus GGCCAGAC (21) at five of eight positions. The P-element insertion at this site within the gene would be expected to alter the carboxyterminal 12 amino acids of tryptophan oxygenase. An insertion at this position might also affect the termination of transcription or translation. However, we have not examined $v$ transcript accumulation in the $v^{\text {H2a }}$ mutant.

\section{DISCUSSION}

The $v^{1}, v^{2}$, and $v^{\mathrm{k}}$ mutants have 412 insertions at identical positions, and the elements are in the same orientation. These observations raise the possibility that these mutations have a common origin, although they were isolated independently, i.e., in different laboratories and at different times $(16,37)$. An alternative explanation would be that specific sequences are recognized as target sites for 412 insertion. Will et al. (44) have shown that a 4-base-pair sequence is duplicated at the insertion site. Our unpublished data indicate that the sequence $5^{\prime}-\mathrm{CACG}-3^{\prime}$ located immediately upstream of the 412 insertion site (Fig. 3) is duplicated. The complement of this sequence, $5^{\prime}$-CGTG-3', is similar to the three other sequenced genomic 412 target site duplications, CTTG (two independent events) and CTGG, but is less similar to the duplication in a free 412 long terminal repeat, ATAG, $(38,44)$. Thus, although the number of target sites sequenced is small, specificity for 412 element insertion sites seems quite probable.

Furthermore, this work has established that the 412 insertions are in the $5^{\prime}$ untranslated region of the $v$ gene and that the RNA synthesized in $s u(s) v$ double mutants is apparently the same size as that in the wild type. A similar $v$ RNA accumulates at a very low level even in the absence of the suppressor mutation, and this low level of expression may be responsible for the leaky phenotype associated with these mutants. These observations raise two questions. First, how is the wild-type sized RNA generated with a 7.5-kb transposon inserted into exon sequences? Second, how does a suppressor mutation act to elevate the level of $v$ mRNA? One mechanism for generating a wild-type-sized RNA would be the excision of transposable element sequences by splicing, either at sites within the $v$ gene or within the element. An alternative mechanism would be the initiation of transcription at a different site, either in transposon sequences adjacent to the $v$ coding region or in $v$ sequences just downstream of the insertion.

It was important to define $v$ splice junctions in the vicinity of the 412 insertion in order to determine whether wild-type strains have alternative splicing mechanisms that could eliminate the transposable element sequences at $v$. Although our experiments suggest that more than one transcription start site may be used, we have not detected alternatively spliced 
products. Our S1 mapping experiments demonstrated conclusively that all wild-type $v$ mRNAs include sequences from the 412 insertion site. This result eliminates the trivial explanation that the 412 insertion would be in an intron of a minor species of $v$ RNA. In addition, there are no splice donor sites in $v$ sequences upstream of the 412 insertion which could be spliced to a downstream acceptor to eliminate 412 sequences from the RNA. Therefore, these results suggest that if the 412 sequences are removed from the RNA by splicing, this event would involve sequences that are not normally used in generating the $v$ RNA. Since the insertion is in the untranslated region, the removal of transposon sequences could be imprecise and still produce an RNA which could be translated into a wild-type polypeptide.

Our S1 mapping experiments demonstrated that there are no wild-type transcription initiation sites downstream of the 412 insertion site. Furthermore, it is unlikely that the 412 promoter controls transcription initiation in the insertion mutant because, in the observed orientation, this promoter would direct transcription away from $v$. Therefore, if the site of transcription initiation eliminates transposon sequences, the initiation site would also be one that is not normally used in $v$ or 412 DNA. Future experiments will determine whether transposon sequences are removed by splicing or by initiation at a new site and define how $s u(s)$ mutations alleviate the effect caused by 412 insertion.

\section{ACKNOWLEDGMENTS}

We thank M. L. Tate and M. Meltzer for providing technical assistance; B. Kay, G. Maroni, and P. Pukkila for critically reading the manuscript; S. Whitfield for producing the artwork: and S. Lennon for typing the manuscript.

The initial phase of this research was performed at the National Institute of Environmental Health Sciences, where L.L.S. was a senior staff fellow. This work was supported by National Institute of Environmental Health Sciences intramural research funds. by grant DCB-8602354 from the National Science Foundation, and by Basil O’Connor Starter Scholar Research Award no. 5-642.

\section{LITERATURE CITED}

1. Baillie, D. L., and A. Chovnick. 1971. Studies on the genetic control of tryptophan pyrrolase in Drosophila melanogaster. Mol. Gen. Genet. 112:341-353.

2. Bermingham, J. R., Jr., and M. P. Scott. 1988. Developmentally regulated alternative splicing of transcripts from the Drosophila homeotic gene Antennapedia can produce four different proteins. EMBO J. 7:3211-3222.

3. Biggs, J., L. L. Searles, and A. L. Greenleaf. 1985. Structure of the eucaryotic transcription apparatus: features of the gene for the largest subunit of Drosophila RNA polymerase II. Cell 42:611-621.

4. Bingham, P. M., R. Levis, and G. M. Rubin. 1981. Cloning of DNA sequences from the white locus of $\mathrm{D}$. melanogaster by a novel and general method. Cell 25:693-704.

5. Breathnach, R., and P. Chambon. 1981. Organization and expression of eukaryotic split genes coding for proteins. Annu. Rev. Biochem. 50:349-383.

6. Calzone, F. J., R. J. Britten, and E. H. Davidson. 1987. Mapping gene transcripts by nuclease protection and cDNA primer extension. Methods Enzymol. 152:611-632.

7. Chang, D.-Y., B. Wisely, S.-M. Huang, and R. A. Voelker. 1986. Molecular cloning of suppressor of sable, a Drosophila melanogaster transposon-mediated suppressor. Mol. Cell. Biol. 6: $1520-1528$.

8. Chou, T.-B., Z. Zachar, and P. M. Bingham. 1987. Developmental expression of a regulatory gene is programmed at the level of splicing. EMBO J. 6:4095-4104.

9. Corces, V., A. Pellicer, R. Axel, and M. Meselson. 1981. Integration, transcription, and control of a Drosophila heat shock gene in mouse cells. Proc. Natl. Acad. Sci. USA 78:7038-7042.

10. Dale, R. M. K., B. A. McClure, and J. P. Houchins. 1985. A rapid single-stranded cloning strategy for producing a sequential series of overlapping clones for use in DNA sequencing: application to sequencing the corn mitochondrial 18S rDNA. Plasmid 13:31-40.

11. Hultmark, D., R. Klemenz, and W. J. Gehring. 1986. Translational and transcriptional control elements in the untranslated leader of the heat-shock gene $h s p 22$. Cell 44:429-438.

12. Kozak, M. 1984. Compilation and analysis of sequences upstream from the translational start site in eukaryotic mRNAs. Nucleic Acids Res. 12:857-872.

13. Kubli, E. 1986. Molecular mechanisms of suppression in Drosophila. Trends Genet. 2:204-209.

14. Kuroiwa, A., E. Hafen, and W. J. Gehring. 1984. Cloning and transcriptional analysis of the segmentation gene fushi tarazu of Drosophila. Cell 37:825-831.

15. Levis, R., K. O'Hare, and G. M. Rubin. 1984. Effects of transposable element insertions on RNA encoded by the white gene of Drosophila. Cell 38:471-481.

16. Lindsley, D. L., and E. H. Grell. 1968. Genetic variations of Drosophila melanogaster. Publication no. 627. Carnegie Institution, Washington, D.C.

17. Maniatis, T., E. F. Fritsch, and J. Sambrook. 1982. Molecular cloning: a laboratory manual. Cold Spring Harbor Laboratory, Cold Spring Harbor, N.Y.

18. Melton, D. A., P. A. Krieg, M. R. Rebagliati, T. Maniatis, K. Zinn, and M. R. Green. 1984. Efficient in vitro synthesis of biologically active RNA and RNA hybridization probes from plasmids containing a bacteriophage SP6 promoter. Nucleic Acids Res. 12:7035-7056.

19. Modollel, J., W. Bender, and M. Meselson. 1983. Drosophila melanogaster mutations suppressible by the suppressor of Hairy-wing are insertions of a 7.3-kilobase mobile element. Proc. Natl. Acad. Sci. USA 80:1678-1682.

20. O'Hare, K., R. Levis, and G. M. Rubin. 1983. Transcription of the white locus in Drosophila melanogaster. Proc. Natl. Acad. Sci. USA 80:6917-6921.

21. O'Hare, K., and G. M. Rubin. 1983. Structures of P transposable elements and their sites of insertion and excision in the Drosophila melanogaster genome. Cell 34:25-35.

22. Parkhurst, S., and V. Corces. 1985. Forked, gypsys, and suppressors in Drosophila. Cell 41:429-437.

23. Parkhurst, S. M., and V. G. Corces. 1986. Interactions among the gypsy transposable element and the yellow and the suppressor of Hairy-wing loci in Drosophila melanogaster. Mol. Cell. Biol. 6:47-53.

24. Parkhurst, S. M., and V. G. Corces. 1987. Developmental expression of Drosophila melanogaster retrovirus-like transposable elements. EMBO J. 6:419-424.

25. Parkhurst, S. M., D. A. Harrison, M. P. Remington, C. Spana, R. L. Kelly, R. S. Coyne, and V. G. Corces. 1988. The Drosophila $s u(H w)$ gene, which controls the phenotypic effect of the gypsy transposable element, encodes a putative DNA-binding protein. Genes Dev. 2:1202-1215.

26. Phillips, J. P., and H. S. Forrest. 1980. Ommochromes and pteridines, p. 542-623. In M. Ashburner and T. R. F. Wright (ed.), The genetics and biology of Drosophila, vol. 2d. Academic Press, Inc., New York.

27. Pirrotta, V., and C. Brockl. 1984. Transcription of the Drosophila white locus and some of its mutants. EMBO J. 3:563-568.

28. Poole, S. J., L. M. Kauvar, B. Drees, and T. Kornberg. 1985. The engrailed locus of Drosophila: structural analysis of an embryonic transcript. Cell 40:37-43.

29. Proudfoot, N. J., and G. G. Brownlee. 1976. The 3' non-coding sequences in eukaryotic messenger RNA. Nature (London) 263:211-214.

30. Quarless, S. A., and G. Heinrich. 1986. The use of complementary RNA and S1 nuclease for the detection and quantitation of low abundance mRNA transcripts. Biotechniques 4:434-438.

31. Rubin, G. M. 1983. Dispersed repetitive DNAs in Drosophila, p. 329-361. In J. A. Shapiro (ed.), Mobile genetic elements. Academic Press, Inc., New York. 
32. Sanger, F., A. R. Coulson, B. G. Barrell, A. J. H. Smith, and B. A. Roe. 1980. Cloning in single-stranded bacteriophage as an aid to rapid DNA sequencing. J. Mol. Biol. 143:161-178.

33. Scherer, G., C. Tschudi, J. Perera, H. Delius, and V. Pirrotta. 1982. B104, a new dispersed repeated gene family in Drosophila melanogaster and its analogies with retroviruses. J. Mol. Biol. 157:435-451.

34. Schwartz, H. E., T. J. Lockett, and M. W. Young. 1982. Analysis of transcripts from two families of nomadic DNA. J. Mol. Biol. 157:49-68.

35. Searles, L. L., R. S. Jokerst, P. M. Bingham, R. A. Voelker, and A. L. Greenleaf. 1982. Molecular cloning of sequences from a Drosophila RNA polymerase II locus by $\mathrm{P}$ element transposon tagging. Cell 31:585-592.

36. Searles, L. L., and R. A. Voelker. 1986. Molecular characterization of the Drosophila vermilion locus and its suppressible alleles. Proc. Natl. Acad. Sci. USA 83:404-408.

37. Shapard, P. B. 1960 . A physiological study of the vermilion eye color mutants of Drosophila melanogaster. Genetics 45:359-376.

38. Shepard, B. M., and D. J. Finnegan. 1984. Structure of circular copies of the 412 transposable element present in Drosophila melanogaster tissue culture cells, and isolation of a free 412 long terminal repeat. J. Mol. Biol. 180:21-40.

39. Spana, C., D. A. Harrison, and V. G. Corces. 1988. The Drosophila melanogaster suppressor of Hairy-wing protein binds to specific sequences of the gypsy retrotransposon. Genes Dev. 2:1414-1423.

40. Staden, R. 1980. A new computer method for the storage and manipulation of DNA gel reading data. Nucleic Acids Res. 8:3673-3694.

41. Tartof, K. D. 1969. Interacting gene systems. I. The regulation of tryptophan pyrrolase by the vermilion-suppressor of vermilion system in Drosophila. Genetics 62:781-795.

42. Thomas, P. S. 1980 . Hybridization of denatured RNA and small DNA fragments transferred to nitrocellulose. Proc. Natl. Acad. Sci. USA 77:5201-5205.

43. Walker, A. R., A. J. Howells, and R. G. Tearle. 1986. Cloning and characterization of the vermilion gene of Drosophila melanogaster. Mol. Gen. Genet. 202:102-107.

44. Will, B. M., A. A. Bayev, and D. J. Finnegan. 1981. Nucleotide sequence of terminal repeats of 412 transposable elements of Drosophila melanogaster. J. Mol. Biol. 153:897-915.

45. Yuki, S., S. Inouye, S. Ishimaru, and K. Saigo. 1986. Nucleotide sequence characterization of a Drosophila retrotransposon, 412. Eur. J. Biochem. 158:403-410.

46. Zachar, A., T.-B. Chou, and P. M. Bingham. 1987. Evidence that a regulatory gene autoregulates splicing of its transcript. EMBO J. 6:4105-4111.

47. Zachar, A., D. Garza, T.-B. Chou, J. Goland, and P. M. Bingham. 1987. Molecular cloning and genetic analysis of the suppressor-of-white apricot locus from Drosophila melanogaster. Mol. Cell. Biol. 7:2498-2505.

48. Zachar, Z., D. Davison, D. Garza and P. M. Bingham. 1985. A detailed developmental and structural study of the transcriptional effects of insertion of the copia transposon into the white locus of Drosophila melanogaster. Genetics 111:495-515. 